\title{
The Essence of Morning
}

\author{
Leonor Fernandez, MD
}

Division of General Medicine and Primary Care, Beth Israel Deaconess Medical Center, Harvard Medical School, Boston, MA, USA.

$\mathrm{H}$ ot coffee beckons with its promise of contraband comfort on a cold and busy Monday morning. Ms. H, my first patient, has not arrived yet. I consider a quick dash downstairs to the coffee shop. I can usually make it back in 4 minutes... I glance at my email. You have 2 new PatientSite messages. I stay.

I close the many open windows on my computer and open the link. I approach the blinking vigil of the messages as I might a covered wound - with a mix of curiosity, a desire to help, and a sense of impending doom. I feel two competing desires: to leave the bandage on or lift it off as quickly as possible. A subconscious triage occurs-do I have enough time, attention, and emotional energy to respond in this moment?

The first email is from Diana and it dispels the fog of distracted multitasking. I hear her voice as I read: "Doctora, ¿Como esta? Y la familia...?" She continues, in Spanish: "Thanks for seeing me on Friday. I read your office note. The fever is gone and I am feeling better. Can you schedule the PET scan sooner? Also, when you have a momentico, can you give me a call? I want to ask you about some of the blood tests. Affectionately, Diana"

$$
* * * *
$$

Flash forward. Diana died a year ago of metastatic colon cancer. Even so, my computer still suggests her name as I type the letter " $D$ ". In retrospect, her emails often required some time, but they didn't feel burdensome. Her tone was a unique blend of affection, familiarity, and matter-of-fact authority.

Her life defied expectations in many ways. She lived 8 years following her diagnosis, much longer than most people with her illness. She displayed more savvy and selfassurance than many expected from someone with her educational background. She used technology to jump over the linguistic barriers she faced, asking politely but insistently for tests and procedures. Her keen intelligence and strong sense of self quickly charmed the doctors, nurses, and aides who came to know her. Many would visit her during her frequent admissions.

Our electronic correspondence gave us a sense of intimacy, but her emails did not reveal her deeper thoughts. She followed the carcinoembryonic antigen (CEA) level

Published online September 5, 2012 closely, noting carefully how it fell and then rose, but she kept her emotions largely hidden. Perhaps I should have tried to encourage her more explicitly to share her feelings on email, since she usually would not discuss them during our visits. But she was not someone who talked or wrote about her feelings. She fiercely guarded her capacity to hope for a different prognosis. At times, I sensed that both of us would become too vulnerable if she truly shared her fears. In the hospital I kept my gaze steady on her face, the white sheets barely shielding us from the continuous reminder that lay below, an inexorable wound. Her upbeat phone greeting "Allo...?" still resounds in my mind.

Many patients email me, although not as many as I would have imagined. For the past several years, they have been able to check their lab and radiology results online, and they occasionally ask related questions. It is only recently, however, that as participants in OpenNotes, they can also read my visit notes as soon as I sign them. I had braced for impact, fearing a deluge of patient inquiries and comments about my documentation. Few patients, however, actually mention the notes. I am surprised - and a little grateful — not to be receiving more questions or requests for annotations. But silence is also a little unnerving. Have I summarized these visits clearly during conversations in clinic? Are patients surprised? Upset? Do the notes help them or their family better understand their care? When speaking with patients, I try to make sure my words are meaningful. But my office notes - muted incantations dictated quickly into my phone - serve another purpose and presume a different reader. Medical language sounds a distant tone, despite my attempts to offset its detached predictability. Gritty realities hide in the neat folds of assessment and plan. In truth, our notes are intended for other clinicians. The patient is still an accidental reader, outside peering in, as we rush on to hear-and tell - the next story.

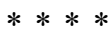

Back to that morning. Another PatientSite e-mail glares at me, highlighted in red to protest its unread state, this one from Mr. W, sent at 12:51 AM. My stress level mounts as I deliberately press $\mathbf{X}$ to close the box. "Later," I think. I can't

J Gen Intern Med 28(4):598-9

DOI: $10.1007 / \mathrm{s} 11606-012-2196-0$

(C) Society of General Internal Medicine 2012 
handle it right now. I feel my heart rate rise. As I try to do something else, I inevitably start thinking about the need to reply. Recently, Mr. W's paranoia has been increasing. His questions have become more pointed and angry, accusations just under the surface. I am careful to read the notes I write about him with a critical eye before signing them, considering how he might interpret a word that carries no intended judgment on my part. With this perspective, many common medical expressions suddenly sound harsh or objectifying. At times, I censor my descriptions, altogether avoiding the word "agitated." $\mathrm{He}$ is alerted automatically whenever I document our interactions, and too much detail can set off an echo chamber of email and phone calls. I sometimes feel trapped. The system records and conveys it all to my patients: the exact hour I read the email, the exact hour I respond. My late night attempts to catch up are suddenly too public. I keep my notes about him as brief and as positive as possible. Our conversations are a chess game, his increasing vigilance mirrored by mine.

Ms. $\mathrm{H}$ has finally arrived, and another patient is already waiting. I pause. Morning light stretches across the floor. I think of the espresso maker Diana gave me a few years ago.
It has a simple, elegant metal design. As it is heated on the stove, the water in the bottom compartment turns to steam. It rises through the middle section, which contains the ground coffee, finally bubbling up to the fluted metal top. The thought of the earthy aroma of espresso sustains me as I enter the room.

Ms. H looks up. She has a deep voice, full of pain and beauty. Her dreams of studying architecture have been shattered by the rheumatologic disease that is destroying her blood vessels. As we talk, her sad face brightens slightly. I listen closely. What we do matters.

I gratefully acknowledge the editorial suggestions and guidance of Dr. Tom Delbanco. I thank Dr. Rafael Campo for his comments on an earlier draft. I am grateful to the family of Diana for their permission to publish this story.

Corresponding Author: Leonor Fernandez, MD; Division of General Medicine and Primary Care, Beth Israel Deaconess Medical Center, Harvard Medical School, 330 Brookline Avenue, Boston, MA 02215. USA (e-mail:Lfernan1@bidmc.harvard.edu). 